\title{
Relação das teses e dissertações defendidas no Programa de Pós-Graduação Stricto Sensu em Educação da Universidade São Francisco no período de dezembro de 2015 a maio de 2016
}

BARBATO, Christiane Novo. A constituição profissional de formadores de professores de matemática. 2016. 322 p. Tese (Doutorado em Educação). Programa de Pós-Graduação Stricto Sensu em Educação, Universidade São Francisco, Itatiba, SP. Orientadora: Profa. Dra. Adair Mendes Nacarato.

O trabalho que ora se apresenta pretendeu investigar de que forma se constitui a identidade do docente formador de professores de Matemática, quais suas crenças e seus saberes sobre o seu trabalho e sobre o futuro trabalho do seu aluno, buscando analisar se essas crenças e a constituição da sua identidade interferem na tessitura do seu fazer profissional nas salas da Licenciatura em Matemática, considerando-se o contexto social e político no qual esse trabalho se desenvolve. Para a consecução desses objetivos, contamos com a colaboração de oito docentes formadores de professores de Matemática, cinco de uma universidade pública federal e três de um Instituto Federal de Educação, cujas entrevistas narrativas foram transcritas e passaram por um processo de transcriação, constituindo-se narrativas de vida. Por meio dessas narrativas, aproximamo-nos das suas trajetórias de vida pessoal, estudantil, de formação e profissional. O presente trabalho foi desenvolvido em uma perspectiva sociológica, tendo como base as ideias de Maurice Tardif, Claude Lessard, Selma Garrido Pimenta e Antonio Nóvoa. Apoiamo-nos também nos conceitos sobre identidade profissional (Claude Dubar, Berger e Luckmann, Antonio Nóvoa e Carlos Marcelo García), sobre estudos biográficos (Maria Helena M.B. Abrahão, Maria Conceição Passeggi; Elizeu C. Souza, dentre outros) e sobre pesquisa narrativa (Daniel Bertaux; Claude Dubar; Clandinin e Connelly). Os conceitos de experiência e de saber da experiência são trabalhados numa perspectiva Larrosiana. A entrevista narrativa mostrou-se um convite à reflexão dos formadores, revelando-se como possibilitadora de tomada de consciência, reconsiderações das crenças e dos saberes, bem como de aprendizado e autoconhecimento. Observamos que a identidade profissional dos formadores se constitui em meio a interações sociais, tendo suas experiências familiares, discentes e docentes como basilares dessa construção. Assim, essa identidade se vê delineada pela concepção que o formador possui sobre o que é ser professor de Matemática, o que supõe sua percepção sobre a Matemática e seu ensino, sobre o aluno e sua formação, e, ainda, sobre seu próprio papel nesse processo. As dificuldades inerentes à própria formação, somadas às condições de trabalho do professor que atua na educação básica, mostraram-se fatores desmotivadores do prosseguimento do licenciando na carreira docente, contribuindo com os altos índices de evasão do curso, o que, percebemos, frustra o formador. A imagem do professor como transmissor de conhecimento, observada em alguns dos formadores, parece ser decorrente de uma formação centrada no ensino dos conteúdos disciplinares e da visão dicotômica do curso, na qual as disciplinas da Matemática Pura aparecem desconectadas das atinentes às das Ciências da Educação. Entendemos que essas crenças, imagens e concepções que constituem a identidade profissional do formador impactam na forma como ele conduz a formação do futuro professor. O rompimento dessas crenças, imagens e concepções apresenta-se em alguns dos formadores, como consequência de reflexões sobre o ensino, a formação, o trabalho docente e a respeito dos atores envolvidos no processo de ensino aprendizagem, mediadas por leituras, professores, pares ou alunos. Os resultados alcançados apontam para a necessidade de que os cursos de Licenciatura em Matemática privilegiem a formação unificada e promovam espaços e tempos para que os professores discutam e reflitam sobre suas práticas, de modo a possibilitar seu aprendizado contínuo, viabilizando que se reconheçam enquanto formadores de professores de Matemática.

Palavras-chave: identidade do docente formador de professores de Matemática; crenças docentes; saberes docentes; entrevista narrativa.

CAPORALE, Silvia Maria Medeiros. Escrever e compartilhar histórias de vida como práticas de (auto) formação de futuros professores e professoras de matemática. 2016. 241 p. Tese (Doutorado em Educação). Programa de Pós-Graduação Stricto Sensu em Educação, Universidade São Francisco, Itatiba, SP. Orientadora: Profa. Dra. Adair Mendes Nacarato.

Esta pesquisa, desenvolvida no curso de Licenciatura em Matemática da Universidade Federal de Lavras, tem 
como foco a constituição da identidade docente de professoras e futuros professores de matemática quando inseridos em práticas de formação compartilhadas. Optou-se pela pesquisa narrativa porque a pesquisadora atuou como professora e mediadora biográfica dos memoriais da professora supervisora do Programa Institucional de Bolsa de Iniciação à Docência (PIBID) e de seis graduandos que foram os sujeitos de pesquisa. Atuou também em outros espaços formativos desse grupo e, portanto, sua história se cruza com as dos sujeitos. Metodologicamente o trabalho se apoia no método biográfico, tendo os memoriais de formação - apropriados à pesquisa narrativa como fonte de dados; teoricamente apoia-se nos estudos relativos à formação docente, identidade docente, histórias de vida e de formação. Buscou-se responder à questão: "Como o(a)s futuro(a)s professores(as) e a professora em exercício vão atribuindo sentido as suas experiências e constituindo a identidade docente, ao participar de práticas de (auto)formação compartilhadas?". Elegeram-se como objetivos: 1) Compreender a constituição das identidades docentes dos sujeitos a partir das histórias de vida; 2) Identificar os elementos que contribuem para a constituição da identidade docente dos sujeitos ao participar de diferentes contextos e práticas (auto)formativas; e 3) Identificar as contribuições do memorial de formação e do grupo de socialização e reflexão, enquanto prática de (auto)formação do futuro professor e professor de matemática. A análise narrativa dos memoriais e dos encontros de mediação biográfica possibilitou interpretações sobre os modos como cada um dos sujeitos constituiu a sua identidade. As identidades profissionais foram se configurando no contexto da família, da escola de educação básica, da universidade e da atuação profissional. Os futuros professores e a professora participaram de uma prática reflexiva de (auto)formação, que pressupõe aprendizagens no âmbito pessoal e profissional, na medida em que puderam voltar o olhar para si mesmos, conhecer-se a partir da dinâmica da mediação da escrita e pelo movimento do pensar sobre o pensar.

Palavras-chave: Professor de matemática. Memorial de formação. Formação inicial. Identidade docente.

PEREIRA, Ângela Maria. Anúncios publicitários divulgados na internet: a elaboração do modelo didático como contribuição para o letramento escolar. 2015. 158p. Tese (Doutorado em Educação) - Programa de Pós-Graduação Stricto Sensu em Educação, Universidade São Francisco, Itatiba, SP. Orientadora: Profa. Dra. Luzia Bueno

Esta tese tem como objetivo principal a elaboração de um modelo didático de anúncios publicitários veiculados na internet a fim de contribuir para o letramento escolar e simultaneamente para uma formação mais crítica de alunos da educação básica frente ao consumismo. A pesquisa baseou-se essencialmente na união do quadro teórico-metodológico do Interacionismo Sociodiscursivo - ISD - (BRONCKART, 1992/2003, 2006, 2008) com a teoria da Gramática do Design Visual (GDV), proposta por Kress e van Leeuwen (1996/2006). O instrumento analítico utilizado foi o modelo de análise Semiótico Sociointeracional proposto por Leal (2011). Esse modelo apresenta uma junção das teorias do ISD e da GDV. Para suporte teórico da construção do modelo didático buscamos apoio em Schneuwly e Dolz (2004). Dentre outras contribuições teóricas, utilizamos os estudos sobre letramentos feitos por Street $(1984,2003,2006,2014)$ e Kleiman $(1995,2005,2014)$. Na realização da análise, foram considerados o contexto de produção e de recepção e as características discursivas, linguístico-discursivas e imagéticas. Esses aspectos investigados foram apresentados e utilizados para a indicação das dimensões ensináveis do gênero foco da pesquisa. O resultado da análise apontou que, para a construção do sentido textual nos exemplares textuais observados, há uma integração do verbal e do não verbal, porém o imagético prepondera como recurso de indução. A partir dos dados observados na análise, fizemos uma proposição de atividades para um trabalho com o ensino de gêneros textuais em sala de aula, nos anos finais do ensino fundamental. Consideramos que, ao realizar essa pesquisa, propiciamos ao contexto educacional reflexões sobre a produção e a interpretação de textos publicitários multimodais e sobre a questão do consumismo no mundo hoje, colaborando, dessa forma, para o letramento escolar.

Palavras-chave: Anúncio Publicitário; Interacionismo Sociodiscursivo; Gramática do Design Visual; Modelo Didático; Letramento Escolar.

SILVA, Vânia de Araújo. O Grupo Escolar de Itaúna: entrelaçando memórias e histórias da educação primária (1908-1924). 2015. 252p. Tese (Doutorado em Educação). Programa de Pós-Graduação Stricto Sensu em Educação, Universidade São Francisco, Itatiba, SP. Orientadora: Profa. Dra. Maria de Fátima Guimarães. 
Este trabalho apresenta aspectos da História da Educação primária em Itaúna, cidade do interior de Minas Gerais, entre os anos de 1908 a 1924. A pesquisa visou ampliar o conhecimento acerca do Grupo Escolar de Itaúna e de alguns sujeitos envolvidos com a educação itaunense no período, em meio a antigas e novas práticas que se faziam presentes em um período marcado por mudanças sociais e econômicas determinantes na sociedade e consequentemente nas instituições educativas. Ressaltamos que no período, imbricado no universo educacional, temos a presença dos ideais que orientaram a Reforma João Pinheiro (1906) em Minas Gerais, tais como: a preocupação com a higiene e salubridade do ambiente escolar, a valorização da disciplina e do controle das pessoas e das práticas, a racionalização do espaço e dos tempos, a criação e a especialização de novas categorias profissionais que passaram a compor a organização escolar, dentre outros aspectos. O objetivo da pesquisa foi ampliar o conhecimento sobre a constituição do Grupo Escolar de Itaúna e os consequentes desdobramentos na história da educação itaunense. Tivemos como objetivos específicos saber quais eram as escolas primárias existentes em Itaúna, antes e após a Reforma João Pinheiro, em 1906 e analisar como a educação escolar em Itaúna era veiculada através da imprensa local no período da constituição de seu primeiro grupo escolar e, entrelaçar histórias da educação primária itaunense e memórias de alunos ou professores, que porventura fossem encontrados. Acreditava-se que não havia um grande volume de fontes relativas a história da educação itaunense ao final do século XIX e início do século XX ou mesmo registros de memórias. Entretanto, pudemos verificar que há um volume considerável de fontes primárias e secundárias, ao contrário do que muitos na cidade acreditavam. Entretanto, os documentos são esparsos, muitas vezes desconhecidos até mesmo por estudiosos. Na perspectiva da história sociocultural da educação, a problematização dessas fontes encontradas se tornou essencial para análise acerca das pessoas, do cotidiano e demais aspectos da instituição escolar. O cruzamento das fontes nos possibilitou apreender como se davam as interações entre algumas pessoas que fizeram a história da instituição pesquisada. Os referenciais teóricos que subsidiaram nosso trabalho estão ancorados nas contribuições de Bakthin (1997), Benjamin (1994), Ginzburg (1989), De Certeau (1979, 2003), Hobsbawm (1995, 1998), Le Goff (1996), Thompson (1981), dentre outros. Os resultados obtidos pela pesquisa de Doutorado têm contribuído para o conhecimento da história da educação local, hoje marcada pela linearidade. Registros e memórias de alguns sujeitos diretamente envolvidos com a educação itaunense, especialmente com o Grupo Escolar de Itaúna foram dados a conhecer. A totalidade de fontes encontradas poderá facilitar o trabalho de novas pesquisas e suscitar futuras temáticas sobre a educação primária itaunense e para o cotejamento com outras pesquisas que têm como objeto os grupos escolares e a educação primária no Brasil e especialmente em Minas Gerais.

Palavras-chave: História da Educação. Grupo Escolar. Memórias.

SWERTS, Márcio Moterani. O dia "D” da educação em Minas Gerais: jogos estratégicos de poder. 2016. 152p. Tese (Doutorado em Educação). Programa de Pós-Graduação Stricto Sensu em Educação, Universidade São Francisco, Itatiba, SP. Orientador: Prof. Dr. Carlos Roberto da Silveira.

A presente pesquisa busca investigar "quais os sentidos, os efeitos e os jogos estratégicos de poder-saber que a utilização da expressão "Dia D" engendra no contexto da educação mineira?". Para tanto, objetiva-se problematizar, suspeitar e analisar criticamente o discurso presente nos documentos específicos do Dia "D", visando compreender como se dão os jogos de estratégias de poder-saber, sobretudo, em torno da expressão Dia "D". Destacamos que essa pesquisa foi organizada a partir de uma abordagem qualitativa, em que se assumem como referência/inspiração as propostas de análise de discurso foucaultiana, diante do principal documento oficial atinente à organização do Dia "D": o Guia para organização do Dia "D” ("Guia de orientação para a reorganização e implementação do Plano de Intervenção Pedagógica - 2010/2011"). Juntamente com esse documento, analisaremos também, de modo complementar, os discursos referentes ao Dia "D", em especial, presentes no documento: "Guia de revisão e reorganização do Plano de Intervenção Pedagógica - 2013" (este é uma continuidade do documento produzido em 2010/2011). Em vista disso, trabalharemos uma analítica em relação ao poder-saber, ao poder político, ao governamento e às estratégias de governamentalidade, às quais se fazem indispensáveis e peremptórias a esta pesquisa. De resto, as nossas análises nos permitem inferir que o Dia "D" da Educação Mineira possui uma função governamental-pastoral, pois tem como objetivo a construção de um sujeito de consciência (voltado para os resultados, para os índices). Ademais, a figura do sujeito político (Governador de MG) por detrás da produção dos documentos atinentes ao Dia "D", emerge tal qual a figura do "pastor", quer dizer, daquele que guia o rebanho. Mas não é guiar o rebanho no sentido da "salvação", pelo contrário, trata-se de 
guiar no sentido dos resultados, dos melhores índices no IDEB, no PROALFA. Enfim, pode-se inferir que o Dia "D" em MG é uma operação de jogada política que visou à constituição da figura de um sujeito político (Governador de MG) - "soberano" - a ser tomada como referência no cenário político nacional.

Palavras-chave: Dia "D”; Governamentalidade; Poder Pastoral; Avaliação em Larga Escala; Educação Mineira.

\section{Dissertações}

BASSO, Amália Fonte. Memórias e histórias de Padre Aldo Bollini: Olhares e iniciativas educacionais em Bragança Paulista (1948 - 1964). 2016. 175p. Dissertação (Mestrado em Educação). Programa de Pós-Graduação Stricto Sensu em Educação, Universidade São Francisco, Itatiba, SP. Orientadora: Profa. Dra. Maria de Fátima Guimarães.

A pesquisa privilegia a temática da história da educação brasileira e Igreja Católica na relação com a cidade e suas memórias. Apoiando-se nas concepções de autores como Ginzburg, De Certeau, Le Goff, desenvolveu-se a partir da leitura dos periódicos: jornal mensal Garotos (1950 a 1984) e o jornal diocesano A Voz de Bragança (1949 - -), criados por padre Aldo Bollini, na paróquia Santa Terezinha, de Bragança Paulista, e dos periódicos de ampla circulação nesta cidade: Bragança-Jornal, Cidade de Bragança e Tribuna Bragantina em diálogo com outras fontes como arquivos pessoais, fotografias e impressos de memorialistas locais e religiosos, na relação com o cenário da época. Padre Aldo Bollini foi um missionário italiano do Pontifício Instituto das Missões Exteriores PIME que atuou em Bragança Paulista de 1948 até sua morte em 1983 e promoveu iniciativas pela educação e cultura que divergem opiniões até os dias atuais. Fundou dois jornais católicos, construiu a primeira paróquia do PIME no Brasil, fundou o Grupo Escolar Coronel Francisco de Assis Gonçalves, intermediou a construção da primeira unidade do SESI em Bragança, criou um cinema, um teatro e um time de futebol, entre outras iniciativas. Promoveu campanhas anticomunistas e pela erradicação do analfabetismo, dirigindo o Movimento Social Católico, em que orientava os cidadãos para o que chamava de "boa política". A pesquisa teve como objetivos mais amplos identificar e compreender alguns aspectos da trajetória do padre Aldo Bollini nos anos de 1948 a 1964 a fim de analisar e compreender suas iniciativas voltadas à educação, em seu sentido mais amplo para além do âmbito escolar. Com o objetivo específico de identificar ideias que ancoravam sua atuação. Como resultados, identificamos que o padre fazia alianças com industriais, comerciantes e políticos e obtinha vantagens e recursos para a manutenção de suas obras sociais por meio delas. Foi algumas vezes homenageado e em outras, criticado pelos periódicos locais e a partir de 1950 começa a perder visibilidade nesses periódicos e seu nome como redator de A Voz de Bragança é retirado do jornal em 1953, quando o bispo diocesano assume determinadas orientações politicas.

Palavras-chave: Educação e Igreja Católica, Bragança Paulista, padre Aldo Bollini.

COSTA, Maria Clelia Pereira da. Memórias dos pioneiros do projeto de assentamento dirigido Coronel Salustiano e Anauá: "Casa-Escola do Valentin" (Rorainópolis-RR- 1975-1983). Itatiba, 2016. 235 p. Dissertação (Mestrado em Educação). Programa de Pós-Graduação Stricto Sensu em Educação, Universidade São Francisco, Itatiba, SP. Orientador: Prof. Dr. Carlos Roberto da Silveira.

Este trabalho é resultado de dois anos de investigação em áreas de assentamento, pesquisando sobre o contexto histórico dos Projetos de Assentamento Dirigido Coronel Salustiano de Farias Vinagre e Anauá (PAD/CSFV/ANAUÁ), criados na BR 174 no período de (1975-1979) no ex-Território Federal de Roraima. A investigação teve como objeto de estudo a primeira Casa-Escola do segundo maior assentamento de terra do Brasil. A pesquisa se pauta nas experiências de vida de quatorze migrantes integrantes desse projeto residentes no município de Rorainópolis e Boa Vista-RR. A investigação percorreu os caminhos metodológicos da História Oral, para dar vozes às memórias dos construtores desses espaços conquistados, atravessados pelas lutas e tensões da posse da terra e do direito a escola do assentamento. Nesse aspecto, o objetivo principal norteador deste estudo foi: Construir as memórias dos projetos de assentamento Coronel Salustiano e Anauá a partir das narrativas dos pioneiros formadores desse movimento analisando a importância da instalação e funcionamento da Casa-Escola do km 475 como identidade constituinte de mudanças na vida dos migrantes da BR 174, ocupantes dos espaços de 
aprendizagem, trabalho e esperança. Conhecer o movimento de construção do Povoado Vila do Incra, suas nuances históricas, e os sujeitos envolvidos na gênese desse lugar. Avaliar os embates políticos e sociais na instalação e funcionamento da primeira Casa-Escola desse assentamento. Diante do exposto, procurou-se responder ás questões norteadoras da pesquisa: Como a inserção dos migrantes nordestinos se justificou nesse meio Amazônico, gerando esse movimento de assentamento e construção de uma nova cidade às margens da BR 174? Em que aspecto a Casa-Escola se constituiu um clamor dos pioneiros pela educação do assentamento de terra? A pesquisa utilizou as fontes documentais constituídas de relevância considerando os estudos de Le Goff (1990) e seu repertório sobre questões referentes ao documento monumento e as diferentes memórias. Nos estudos de Ginzburg, $(1989,2005)$ nos embasamos a partir do paradigma indiciário no sentido de buscar os vestígios da escola. Para a pesquisa de campo nos orientamos pelas técnicas de Paul Thompson (1992) Meihy \& Holanda (2007) Caldart (2004) traz contribuições relevantes sobre a pedagogia da terra. Bergamasco $(1996,1997)$ e Luiz Norder (1997), abordam a importância dos assentamentos, e os pesquisadores roraimenses: Freitas, $(2009,1997)$ Barros (1995), Magalhães (2008) e Mourão, (2008) tratam da história, historiografia e geografia de Roraima e apresentam importantes contribuições para compreensão da história do lugar.

Palavras-chave: Assentamento Coronel Salustiano. Memórias dos Pioneiros. Casa-Escola.

DIAS, Kate Paula Nunes. Legislação e educação da infância na coleção de leis do império (1808-1889). 2015. 225p. Dissertação (Mestrado em Educação). Programa de Pós-Graduação Stricto Sensu em Educação, Universidade São Francisco, Itatiba, SP. Orientadora: Profa. Dra. Luzia Batista de Oliveira Silva.

Essa dissertação apresenta resultados de pesquisa, reflexões sobre os embates, tensões, disputas e desdobramentos que permearam o contexto histórico sobre a educação na infância e suas relações sociais, especificamente no século XIX. Como fonte principal de pesquisa, tem-se a Coleção de Leis do Império (1808-1889), publicada e digitalizada pela Imprensa Nacional. Toma-se como ponto de partida a análise do mapeamento de cartas de leis, cartas régias, alvarás, decretos, leis e decisões imperiais, referente a medidas que envolviam crianças e adolescentes no período compreendido entre 1808 a 1886, material disponibilizado na página "História da Educação e da Infância", da Fundação Carlos Chagas, sob o título Legislação sobre Infância no Império do Brasil. As reflexões, considerações e discussões sobre a infância no âmbito histórico oitocentista permitiram contextualizar as iniciativas traçadas e efetivadas no governo imperial com relação às crianças numa análise mais aprofundada, pautada pelo cotejo das fontes legislativas com a bibliografia existente sobre esse período. A pesquisa identificou instituições e buscou compreender as propostas para a educação da infância, em diferentes situações e condições sociais, relacionandoas aos aspectos políticos, econômicos, sociais e religiosos ocorridos no país. A sistematização inicial da documentação legislativa referente à infância permitiu apontar e analisar diferentes instâncias administrativas e instituições públicas e privadas em território nacional, envolvidas na criação e manutenção de medidas assistenciais e educacionais direcionadas às crianças. Nesse levantamento, os documentos foram classificados e agrupados de acordo com as instituições específicas para a assistência infantil, envolvendo medidas referentes a instituições de assistência à infância desvalida, como as Casas Pias, as Casas da Roda de Expostos, os Seminários, os Asilos, as Casas de Educação, as Escolas, os Recolhimentos, os Colégios, as instituições de assistência aos libertos e aos indígenas, os institutos para deficientes e as Instituições Militares e Navais. Os textos trouxeram informações referentes aos objetivos dessas organizações, a forma como eram mantidas, destacando seus critérios para admissão e permanência das crianças, além de sua distribuição pelas províncias. As fontes contribuíram para a coleta de informações referentes aos aspectos funcionais e organizacionais desses estabelecimentos e possibilitaram a verificação e identificação da maior ou menor presença de medidas ao longo desses anos, que indicaram uma periodização interna, como na vinda de D. João VI ao Brasil; como após a Independência; a Constituição de 1824; o Ato Adicional de 1834; a Lei do Ventre Livre; entre outros marcos que exerceram reais influências na estruturação e organização dessas entidades com focos educacionais.

Palavras-chave: Legislação. Educação. Império. Instituições. Infância.

FREITAS, Andréia Pinheiro de. Processos de subjetivação e a escrita de si em contexto militar: uma análise discursiva. 2016. 99p. Dissertação (Mestrado em Educação). Programa de Pós-Graduação Stricto Sensu em Educação, Universidade São Francisco, Itatiba, SP. Orientador: Prof. Dr. Carlos Roberto da Silveira. 
Coorientadora: Prof ${ }^{a}$ Dra. Márcia Aparecida Amador Mascia.

Os discursos que permeiam toda e qualquer discussão sobre educação são extremamente marcados pelas relações sociais, políticas, culturais e ideológicas que são vivenciadas pelos sujeitos da história. A língua, portanto, que reflete parte do conjunto simbólico desses discursos, constitui-se em um poderoso meio de significação e ressignificação dos mais variados gêneros e uma das formas mais importantes para a análise desses mesmos discursos. É no contexto dessas discussões, embasada nas teorias foucaultianas sobre processos de subjetivação e escrita de si e nas teorias enunciativas e discursivas de linguagem, que a presente pesquisa teve como objetivo geral observar as marcas de objetivação e subjetivação que se evidenciam em textos de alunos em formação militar, após a interação com imagens de vídeos produzidos por outros alunos em contextos diferentes. Partiu-se, para tanto, das seguintes perguntas de pesquisa: De que forma vídeos produzidos por jovens de outros contextos culturais que enfocam questões do ambiente escolar podiam servir de objetos para que alunos-militares partissem para processos de escrita e, em especial, da escrita sobre a organização da rotina de uma escola militar e da escrita sobre si (escrita de si) no interior dessa instituição? De que forma algumas das "marcas" textuais, ao serem problematizadas, podiam produzir (ou não) espaços reflexivos que apontassem para os processos de subjetivação a que estão submetidos, bem como para pontos de fugas produzidos por eles? Para que a pesquisa fosse viabilizada, o corpus foi composto por 04 (quatro) textos escritos por alunos do $1^{\circ}$ ano do Curso de Formação e Graduação de Oficiais de Carreira da Linha de Ensino Militar Bélico do Exército Brasileiro, da Escola Preparatória de Cadetes do Exército, em Campinas, São Paulo. Como referencial teórico, buscou-se apoio nas teorias de Michel Foucault, principalmente em escritos produzidos no final de sua vida, momento em que procurou concentrar-se mais nos questionamentos sobre subjetividade. Além das teorias foucaultianas, buscou-se suporte teórico na Análise do Discurso de Linha Francesa, a fim de levantar efeitos de sentido ao observar a materialidade linguística presente nos textos produzidos após a interação com imagens de vídeo. Na análise discursiva dos textos da presente pesquisa, evidenciaram-se regularidades marcadas pela escolha de palavras que remetiam a determinados campos lexicais de legitimação em relação ao poder disciplinar a que estão submetidos, bem como regularidades marcadas por modalizações discursivas que demonstraram os processos de subjetivação pelos quais os sujeitos são constituídos. O trabalho, dessa forma, lança um olhar sobre as percepções e questionamentos em relação à rotina da vida militar que emergem da "escrita de si" de sujeitos em início de formação militar.

Palavras-chave: subjetividade, escrita de si, análise do discurso, educação.

GARCIA, Sandra Regina Aguiar. O movimento de uma professora na constituição de um ambiente investigativo com alunos do $7^{\mathbf{0}}$ ano do Ensino Fundamental. 2015. 139p. Dissertação (Mestrado em Educação). Programa de Pós-Graduação Stricto Sensu em Educação, Universidade São Francisco, Itatiba, SP. Orientadora: Prof. a Dra. Daniela Dias dos Anjos

Este trabalho de pesquisa de mestrado tem como objetivo investigar o processo vivido por uma professora durante a implementação de um ambiente investigativo de aprendizagem. Com isso, observa-se as mediações envolvidas na aplicação de tarefas exploratório-investigativas e o modo como essas mediações colaboram (ou não) na elaboração conceitual durante o desenvolvimento de conceitos. A produção de dados foi realizada no $7^{\circ}$ ano do Ensino Fundamental em 2014, sala em que a pesquisadora é professora. Tendo como base a proposta de Investigações Matemáticas - que prevê introdução da tarefa, a realização da investigação e a discussão dos resultados -, foram elaboradas sequências didáticas abordando o tema "área e perímetro". Ao todo foram sete as tarefas realizadas. Todo o trabalho desenvolvido foi audiogravado e videogravado. Além desses registros, outros compõem os dados da pesquisa: materiais produzidos pelos alunos na resolução de situações-problema (relatórios e diagramas) e diários de campo da professora-pesquisadora. Analisou-se o processo de mediação entre aluno e professora e os fatores que influenciaram a elaboração conceitual diante da análise dos registros orais e escritos nas situações experienciadas. A análise dos dados segue três eixos: a intencionalidade da professora, o modo de intermediação da professora e a forma como ela registra e percebe a intermediação. Nos resultados discorre-se sobre o processo da professora de flagrar-se diante da heterogeneidade do modo de aprender dos alunos, sobre o uso de instrumentos no processo de elaboração conceitual e sobre as diferentes formas de ressignificação de uma tarefa investigativa.

Palavras-chave: Investigações matemáticas. Matemática. Mediações. Ensino de matemática. 
SOUZA, Sandra Aparecida de. "El terrible anarquista" Joseph Jubert: por entre rastros, memórias e histórias. 2016. 179p. Dissertação (Mestrado em Educação). Programa de Pós-Graduação Stricto Sensu em Educação, Universidade São Francisco, Itatiba, SP. Orientadora: Profa. Dra. Maria de Fátima Guimarães.

Nesta pesquisa, privilegiei a trajetória do professor anarquista Joseph Jubert, em Bragança e segui seus rastros até Sorocaba e Bauru, cidades do interior do estado de São Paulo. Identifiquei, na singularidade de sua trajetória, ações que vieram ao encontro de potencialidades que ampliaram meu olhar para a história da educação. Potencialidades imbricadas no movimento operário que estimularam, para além de uma visão oficial e afeita ao universo escolar, um olhar atento para as tensões e conflitos ancorados em dissonantes concepções do que era educar e percepções do que significava ser professor. Para tanto, parti de um processo-crime (1911), em que Jubert foi citado como réu em decorrência da distribuição de um Boletim da Liga Operária, denunciando as precárias condições de vida dos colonos nas fazendas de café da região, na relação com outras fontes primárias do período, que me levaram a descobrir que ele foi preso em Sorocaba, em 1913, e me permitiram segui-lo até Bauru (1915). O recorte temporal da pesquisa situa-se no período posterior à Proclamação da República (1889), acolhendo a consolidação das relações de trabalho assalariado, matizadas por significativas manifestações e greves operárias até 1920. Os objetivos da pesquisa foram rastrear, cotejar e analisar possíveis concepções de educação e de professor mobilizadas nas fontes primárias pesquisadas, na relação com o modelo educacional dos grupos escolares, tomado como exemplar pelo governo republicano paulista em detrimento de outras possíveis alternativas para a educação. Problematizar e analisar como o professor Jubert e suas ações foram apresentados no decorrer do processo (1911) do Poder Judiciário à comunidade. E identificar se Joseph Jubert foi citado pelos periódicos bragantinos da época e obras de memorialistas locais, visando cotejar as possíveis referências à sua trajetória, ações em Bragança, com notícias e informações acerca dos professores que atuavam no primeiro grupo escolar da cidade, o Doutor Jorge Tibiriçá. Para atingir tais objetivos, priorizei a análise de fontes primárias periódicas (jornais, almanaques, anuários e revistas) e de processos-crime (1911), bem como, fiz a revisão bibliográfica da história de Bragança, da imigração, da instrução pública e também do primeiro grupo escolar de Bragança e da instrução libertária nos princípios de Ferrer, buscando aportes sobre o movimento operário e anarquista, no período, considerando as questões mais amplas da história da educação brasileira na modernidade. Esta pesquisa justifica-se pela inexistência de outras que privilegiem esse tema e objetivos, até o presente momento na cidade, bem como, possibilitará um olhar mais abrangente acerca dos possíveis imbricamentos da história da educação com o movimento operário brasileiro, no período, contribuindo, também, para a construção de conhecimentos históricos sobre Bragança Paulista. O referencial teórico desta pesquisa assenta-se, sobretudo, nas contribuições de E. P. Thompson, C. Ginzburg e W. Benjamin.

Palavras-chave: Joseph Jubert; Processo-crime; Movimento Operário.

MINGARELLI, Kátia Tramontano. (Dis)cursos de professores polivalentes em formação: a língua inglesa em questão. 2016. 123p. Dissertação (Mestrado em Educação). Programa de Pós-Graduação Stricto Sensu em Educação, Universidade São Francisco, Itatiba, SP. Orientadora: Profa. Dra. Márcia Aparecida Amador Mascia.

Esta pesquisa, fruto dos muitos questionamentos levantados ao longo da profissão docente, insere-se na área de Educação e na linha de pesquisa de Práticas Discursivas, Processos Culturais e Educativos e tem como objetivo levantar os discursos de professores polivalentes sobre a língua inglesa. Do ponto de vista do referencial teórico, pautamo-nos em autores da linha discursiva, Orlandi e Pêcheux e autores que discutem o ensino da língua inglesa, como Prasse e Coracini. Metodologicamente, seguimos os seguintes critérios: foram entrevistados três professores polivalentes que atuam na Rede Municipal de Sumaré, no ensino infantil com crianças entre 4 e 6 anos e que têm formação em Magistério e/ou Pedagogia. As entrevistas foram abertas, gravadas e transcritas, tendo como norte questões elaboradas previamente. Partimos do pressuposto de que, ao enunciar, o sujeitoprofessor polivalente tece discursos que mobilizam a memória discursiva e produz um deslocamento na rede de filiações sócio-históricas e ideológicas de identificação. Os resultados apontam para a necessidade que o professor exterioriza ao dizer que está atualizado, e indicam discursos que reforçam o senso comum de que o domínio de uma segunda língua é condição essencial para o sucesso num mundo globalizado. As análises das entrevistas apontam para duas grandes categorizações que versam sobre: o professor polivalente e a questão da (não) formação e o ensino da língua inglesa e as tensões e disputas entre o professor polivalente e o professor especialista. O trabalho, portanto, busca 
contribuir para um olhar mais atencioso em relação às tensões que existem e permeiam o dia-a-dia dos sujeitos da educação, no caso, os professores (poli)valentes que vivem em uma constante busca do "novo" aprender para sentirem-se (con)temporâneos de seu tempo, um tempo em constante mutação.

Palavras-chave: Discurso; Língua Inglesa; Professor Polivalente; Formação do Professor.

VILAS BOAS, Selma Nascimento. Falar, narrar e desenhar: O processo de elaboração conceitual sobre o tempo, por crianças da educação infantil. 2015. 132p. Dissertação (Mestrado em Educação). Programa de Pós-Graduação Stricto Sensu em Educação, Universidade São Francisco, Itatiba, SP. Orientadora: Profa. Dra. Adair Mendes Nacarato.

O presente trabalho investigou as narrativas das crianças da Educação Infantil sobre o conceito de tempo, para identificar e analisar "Quais as significações sobre o tempo podem ser apreendidas em contextos de sala de aula da Educação Infantil, quando as crianças falam e desenham sobre o tema?”. E teve como objetivos identificar os marcadores temporais que as crianças utilizam em suas falas e desenhos; identificar as noções de tempo explicitadas pelas crianças em contextos planejados para discutir o tema; e captar o movimento de circulação do vocabulário relativo ao tempo em sala de aula e a forma como as crianças vão se apropriando dele. Adotou-se a perspectiva históricocultural como suporte teórico para a discussão do papel da palavra, da memória, do desenho e da elaboração conceitual, ampliada com os estudos sobre narrativas infantis e sobre o conceito de tempo. Tratase de uma pesquisa qualitativa, com crianças entre 4 e 6 anos de idade, em uma escola pública, em parceria entre a pesquisadora e a professora da turma. Os documentos resultantes - as gravações dos encontros; os desenhos ali produzidos pelas crianças; o livro do tempo também elaborado por elas, cuja narrativa individual foi videogravada; e o diário de campo da pesquisadora - geraram dados cuja análise foi feita, considerando o início do trabalho, o desenvolvimento das atividades e a produção do livro. Analisaram-se as falas, as narrativas e os desenhos dos alunos. As narrativas das crianças permitiram acesso a suas culturas de referência, e favoreceram o planejamento de práticas pedagógicas com significado para elas. Os alunos elaboraram conceitos que perpassam as áreas de história e de matemática, apropriaram-se do vocabulário relativo ao tempo e trouxeram indícios de compreensão de passado, presente e futuro. Identificou-se que têm muito a falar sobre o conceito de tempo e revelam sentimentos de afetividade em suas relações familiares. A escola precisa desenvolver propostas para discutir tal tema, para que os marcadores temporais façam sentido para as crianças.

Palavras-chave: Educação Infantil. Narrativas infantis. Elaboração conceitual. Tempo físico e tempo vivido. 